\title{
WAKING LIFE E A MODERNIDADE LÍQUIDA
}

WAKING LIFE AND THE LIQUID MODERNITY

\author{
Aline Isabel Waszak \\ Anne Caroline da Rocha de Moraes \\ Maybel Sulamita de Oliveira \\ Paula Marinelli Martins ${ }^{1}$
}

Resumo: Este artigo visa analisar o filme Waking Life, produzido nos Estados Unidos em 2001, como expressão de seu contexto social. A análise da conjuntura é dada a partir do conceito de Modernidade Líquida forjado pelo filósofo Zygmunt Bauman, conceito que faz referência ao período posterior a Segunda Guerra Mundial, onde ocorre a crise da ideia de Progresso e Civilização, que se estende até os dias atuais. A análise do filme como fonte histórica busca compreender como este expõe os questionamentos e contradições da sociedade em que ele foi produzido e consumido, revelando elementos que Bauman expõe em sua tese.

Palavras-chave: Modernidade Líquida, Waking Life, Cinema, PósModernidade, História Contemporânea, Bauman.

Abstract: This article intend to analyze the movie Waking Life, produced in the United States in 2001 as an expression of it's social context. The analysis of the circumstances is given by the concept of Liquid Modernity wrought by the philosopher Zygmunt Bauman, a concept that refers to the period after World War II, where we have the crisis of the idea of Progress and Civilization, which extends to the present days. The analysis of the film as a historical source seeks to understand how this movie exposes the questions and contradictions of the society in

\footnotetext{
${ }^{1}$ As autoras são todas concluintes do curso de licenciatura com bacharelado em História pela Universidade Federal do Paraná. O presente artigo é resultado do trabalho final da disciplina de História Contemporânea II, ministrada no segundo semestre do ano de 2013.
} 
which it was produced and consumed, revealing elements that Bauman explains in his thesis.

Keywords: Liquid Modernity, Waking Life, Movies, Postmodernity, Contemporary history, Bauman.

"Durante anos, a noção de que vida é um sonho foi um tema recorrente entre filósofos e poetas. Não faz sentido que a morte também seja envolta pelo sonho? Que após a morte a vida consciente continue em um corpo de sonho? Seria o mesmo corpo de sonho que aquele da vida cotidiana, mas, no estado pós-morte, não se poderia voltar a despertar. Nunca mais se poderia retornar ao corpo físico. (ALMEIDA, 2007: 61)" ${ }^{2}$

O presente trabalho buscará, através de bibliografia apropriada e da análise do filme Waking Life, perceber se há aplicabilidade do conceito de Modernidade Líquida, apresentado por Bauman, na sociedade em que este filme foi produzido e comercializado.

Considerando que faremos uma análise histórica da obra cinematográfica, é necessária uma breve descrição a respeito das possibilidades da aproximação entre história e cinema. Utilizando como pressuposto o levantamento dos debates e conceitos teórico-metodológicos a cerca dessa temática, por Marc Ferro, Monica Almeida Kornis, Eduardo Borges e Eduardo Victorio Morettin, buscaremos ligações acerca dos encontros desses dois pólos diferentes, mas que podem se interligar em diversos aspectos e utilizações. O cinema como fonte histórica ganhará espaço a partir da década de 70, sob a influência da Escola dos Annales advinda da França, juntamente ao que podemos hoje chamar de uma

${ }^{2}$ Todos os diálogos transcritos do filme foram retirados do anexo do trabalho de Anne Caroline Santilli de Almeida (ALMEIDA, 2007). 
"nova história", essa corrente trouxe a tona diversos trabalhos que se distanciam dos trabalhos realizados apenas com fontes tidas como oficiais, dessa forma, entendemos que o "filme passa a representar um testemunho de seu tempo e ganha o status de documento histórico, assim, algumas obras começam a surgir buscando debater o modo de operar com esta nova fonte" (BORGES, 2005:01).

No campo historiográfico, podemos destacar o historiador francês Marc Ferro como um grande expoente dessa relação entre a história e o cinema. Em sua obra Cinema e História (FERRO, 1992) o autor aponta preposições de como o historiador pode orientar o seu trabalho através da análise de obras cinematográficas. Dentro dessa argumentação o conteúdo das obras está inteiramente relacionado a ideologia de seus produtores, ou seja, eles refletem na obra tanto suas ideias conscientes (a ideia a ser passada através do filme) quanto reflexões insconscientes (aquilo que não era objetivo mostrar mas acaba aparecendo na obra) . Assim, o filme é uma fonte histórica, pois mesmo sem ter uma intenção de se tornar um documento ele representa uma realidade histórica específica.

A metodologia utilizada por Ferro partiria de um primeiro momento analisar o filme de maneira aparente, no âmbito visual; pois as imagens teriam grande importância, já que são o elemento central da obra. Num segundo momento é preciso atentar-se aos elementos mais sutis, como os sons, a trilha sonora, fotografia, etc; pois também nelas são refletidas as escolhas dos produtores. Segundo Eduardo Victorio Morettin para Ferro, "o cinema é um testemunho singular de seu tempo, 
pois está fora do controle de qualquer instância de produção, principalmente o Estado" (MORETTIN, 2003:13). Mesmo que a priore não haja intervenção estatal diretamente na produção analisada, é preciso "reconhecer que existe uma manipulação ideológica prévia das imagens, assim como uma articulação da linguagem cinematográfica com a produção filme" (KORNIS, 2013:239). Desse modo, questionar o discurso e as imagens propostas pela obra é o primeiro passo para analisá-la historicamente.

\section{O filme}

Waking Life, quinto filme da carreira do diretor Richard Linklater, foi produzido no ano de 2001 nos Estados Unidos. Linklater é conhecido por ser um dos maiores nomes da produção independente, tanto que foi indicado ao Independent Spirit Awards quatro vezes, inclusive pelo filme analisado, Waking Life. Mesmo dirigindo filmes de baixo orçamento e que fogem de uma temática mais popularizada, ele foi indicado ao OSCAR de melhor roteiro em 2004, pelo filme Before Sunset. É ainda conhecido como um grande expoente em relação as novas técnicas, a maneira de representar sentimentos através de cores e desenhos, e por fim, e ao longo tempo para gravar e/ou editar os filmes.

Por exemplo, Waking Life demorou 9 meses na parte de edição pois foi gravado inicialmente com atores reais, e cada cena foi redesenhada. Foram 30 animadores, a cada um foi designado um personagem para garantir diferentes gráficos e tipos de desenhos. Desse modo, 
Waking Life que era um filme live action ${ }^{3}$, após sua edição final se transformou em uma animação (ALMEIDA, 2007:13).

Waking Life não se apresenta como a maioria dos filmes de animação, ele se caracteriza por uma particularidade devido a sua nãolinearidade e a variáveis visuais presentes em cada cena; o filme deixa claro que o limite entre a realidade do personagem e realidade de seus sonhos se encontram e se dissolvem a ponto de não haver uma clara separação entre os dois momentos da história, assim nesses "sonhos" o personagem principal tem encontros com diversas pessoas, aparentemente não conhecidas, que dissertam sobre os estados da consciência, da biologia e ligação com a filosofia . Essa particularidade do filme e as cenas com grandes utilizações de cores e discursos entre os personagens agregam a obra um caráter particular e investigativo para o desfecho do filme.

\section{Modernidade Líquida}

Foi nos anos 2000 que Zygmunt Bauman publicou seu livro Modernidade Líquida. Esse livro nos traz uma discussão sobre as transformações pelas quais a modernidade sofreu através dos séculos. Segundo Bauman, hoje se vive um novo momento, em que apesar de ainda poder ser chamado de modernidade o é de uma maneira diferente. $\mathrm{O}$ autor usa a metáfora do "líquido, fluído e fluidez" para explicar o atual momento

\footnotetext{
${ }^{3}$ Live action é termo usado para definir obras fílmicas, teatrais ou televisivas que são feitas com atores reais, ou seja, o oposto de animação.
} 
da modernidade; esse momento que é chamado de pós-modernidade por Stuart Hall, ou de segunda modernidade por Ulrich Beck.

Para melhor compreender o que é a modernidade líquida se torna necessária a explicação do que seria a modernidade anterior a esta, que o autor chama de modernidade sólida. Para ele, a modernidade começa quando tempo e espaço são separados da prática cotidiana e entre si. A partir desse momento o tempo passa a ter uma história; uma capacidade de guardar acúmulo. É quando a humanidade se percebe sozinha, "por nossa própria conta" (BAUMAN, 2001:37); Desse modo, acontece o processo de modernização, no qual o ser humano busca transgredir cada avanço seu, se percebe como agente de transformação.

Bauman se questiona se a própria modernidade sólida não foi ela um derretimento dos velhos sólidos. Ele mesmo responde que realmente ela fragmentou os sólidos valores da pré-modernidade, como a família e os costumes feudais, mas os destruiu para depois buscar construir novos sólidos, diferença fundamental entre essa e aquela modernidade. Esses novos sólidos seriam perfeitos, logo, eternos. Então se iniciou um processo de liberação da economia guiada pela racionalidade instrumental. Logo, ao mesmo tempo em que se derretiam os sólidos pré-modernos, se libertava a economia das amarras da família e constituíam-se as bases para um sólido que não se fragmentaria mais.

A sociedade posterior, onde os sólidos já estão quase que completamente arruinados, é a chamada modernidade líquida, e se inicia nas últimas décadas do século XX. Segundo o sociólogo, esta sociedade se tornou rígida; tão rígida que até mesmo a capacidade de questionar suas 
normas "é impedida por força de sua própria futilidade" (BAUMAN, 2001:11). Desse modo, se criaram novas correntes que atam o sujeito, elas nasceram não por vias autoritárias, mas sim, da "flexibilização", do "soltar o freio" (BAUMAN, 2001:11). Agora, o ser humano não consegue encontrar quem os manipula e onde estão os grandes centros de poder.

A metáfora do líquido é utilizada por Bauman por alguns motivos: os fluídos são leves, e estão relacionados ao movimento e a inconstância; eles "não fixam o espaço nem prendem o tempo" (BAUMAN, 2001:8), ou seja, a dificuldade está em mantê-lo fixo, não em modificálo; e por fim, sua leveza faz com que possuam velocidade, movimento. Essas são as características do capitalismo atual, para Bauman, o capitalismo leve. Se modernidade se caracteriza na percepção da humanidade em perceber-se como responsável pelas coisas boas e pelas mazelas do globo, onde estaria a diferença da "antiga" modernidade para a atual?

Para Bauman, existem duas diferenças cruciais: a primeira é a destruição da ideia de que haverá um "final feliz", um telos, ou estágio final perfeito para os seres humanos. E segundo, é a "desregulamentação e a privatização das tarefas e modelos modernizantes" (BAUMAN, 2001:38), ou seja, deveres que eram encarregados de toda humanidade, são agora, fardo para o indivíduo.

Na Modernidade fluída não existe o ímpeto de se preocupar com a civilização, nem mesmo com a sociedade. No discurso pós-moderno, o indivíduo tem dentro de si "todas ferramentas necessárias para o aperfeiçoamento da vida" (BAUMAN, 2001:38). A família e os estamentos 
na pré-modernidade, ou as classes no início da modernidade era identidades impostas aos indivíduos desde seu nascimento. Na modernidade líquida o indivíduo tem liberdade de escolha. Essa "liberdade" é tão grande, que ele não é mais obrigado a exercer a identidade previamente imposta. Para ele ser algo precisa tornar-se o que já é - exercer seu papel.

No primeiro capítulo de seu livro, Bauman fala de como o indivíduo, nesta sociedade, é forçado a ser livre; e essa liberdade de agir, "escolher" pode parecer interessante, mas com a ação e a escolha vêm a responsabilidade pelas consequências. Toda culpa e superação é resultado das ações do indivíduo, não que isto seja verdade, mas é um discurso que acabou convencendo grande parte da humanidade. Por isso, grandes líderes não estão na pauta do dia, visto que ninguém quer se responsabilizar por outras pessoas e nem precisam ser guiadas; quando se reúnem em grupos, essa humanidade não consegue alcançar uma ação coletiva, ela fica presa num sistema em que cada indivíduo mostra como todos humanos superam suas dificuldades individualmente.

A classe, a família e o bairro - exemplos citados por Ulrich Beck e utilizados por Bauman - são "instituições zumbis". Estão mortasvivas, visto que é o indivíduo que vai dar significado e apontar qual é o papel delas. Dentro desse panorama, não existem mais referenciais sólidos e fixos, como eram a família ou a classe; agora o indivíduo não consegue se fixar num local, numa identidade; e a construção de uma identidade individual nunca chega ao fim, não existe uma sensação de estabilidade. Para Stuart Hall, essa dificuldade dos sujeitos que vivem 
na modernidade líquida, chamada de pós-modernidade por ele, ocorre porque houve a desagregação e o deslocamento do sujeito.

O ser humano centrado, chamado de "sujeito iluminista", que têm a "Razão" como seu guia foi sendo continuamente deslocado; isso se deu através de diversos momentos. Ainda na modernidade, através da biologia darwiniana e do nascimento das ciências sociais, o ser humano iluminista foi descentrado pela ideia de que havia grandes estruturas que delineavam nossas atitudes. Esse sujeito chamado sociológico passa, também, a ser questionado a partir de meados do século XX. Hall cita cinco questões que, para ele causam o descentramento do sujeito, resultado no sujeito pós-moderno. Primeiramente, a partir de um novo estudo sobre Marx, o sujeito não é mais visto como singular e possuindo uma razão universal, ele é produto das relações materiais de produção e exploração do trabalho; Freud, com a descoberta do inconsciente mostra que coisas tidas como naturais são expressões das relações sociais gravadas no nosso inconsciente; Saussure mostra que as palavras possuem sua própria história, e que é impossível expressar exatamente através da linguagem o que sentimos; Foucault aponta como o poder disciplinar rege nossos costumes; e por fim, o feminismo apontou que o privado e as questões de identificação são questões políticas (HALL, 2005).

Este panorama que nos é dado por Bauman e Hall é bastante importante para se compreender a sociedade atual em que vivemos e o filme que será analisado. Antes de se iniciar a análise do filme é importante apontar que as categorias criadas por Bauman e Hall serão utilizadas para analisar as cenas do filme Waking Life. E através do filme, que 
está temporalmente dentro das balizas que os autores apontam como Modernidade Líquida ou pós-modernidade, buscaremos compreender se as afirmativas apontadas nos livros são correspondentes ou não com as representações sociais retratadas no filme. A partir dessa análise buscaremos encontrar a resposta pra questão "Estamos na Modernidade Líquida?". Para melhor organizar separamos a análise do filme em dois conceitos: tempo/espaço e indivíduo.

\section{Tempo/Espaço}

Um primeiro conceito a ser aprofundado neste trabalho é o que se refere às relações entre tempo e espaço constituintes da chamada "modernidade líquida", principalmente a partir das reflexões de Baumam no terceiro capítulo intitulado "Tempo/Espaço". O espaço seria o que se pode ocorrer em certo tempo, e o tempo é o que precisa para percorrer o espaço. Bauman escreve a partir de uma perspectiva comparativa, partindo de uma realidade pesada comparando com a situação líquida pósmoderna. Sendo assim, para explicar o conceito pós-moderno de tempo e espaço, o autor refere-se ao espaço físico como principal constituinte da modernidade pesada, a era da conquista territorial, determinada fisicamente. Sendo assim, a definição de espaço pós-moderno se articula com a noção de que na modernidade o espaço pesado podia ser medido territorialmente, fisicamente, e por sua vez o tempo, também funcionaria de forma determinada e limitada. No mundo fluido, espaço e tempo se aproximam e se separam, o tempo torna-se maleável e mutável, uma vez que com o aumento da velocidade das máquinas e as inovações do mun- 
do tecnológico passou-se a caber muito mais coisas dentro do tempo (BAUMAN, 2001). No filme Waking Life, o oitavo diálogo acompanhado pelo receptor, não conta com a presença do protagonista. É composto por um casal que debate a relação entre tempo/espaço/alma. Ao debater a possibilidade de a vida na verdade estar sendo assistida na hora da morte. Problematiza essa possibilidade a partir do tempo como ele nos aparece nos sonhos:

- Ouvi dizer que Tim Leary, quando estava morrendo, disse que olhava para o seu corpo que estava morto, mas seu cérebro estava vivo. Aqueles seis a doze minutos de atividade cerebral depois que tudo se apaga. Um segundo nos sonhos é infinitamente mais longo do que na vida desperta, entende?

- Claro. Tipo, eu acordo às $10 \mathrm{~h} 12 \mathrm{~min}$ então eu volto a dormir e tenho sonhos longos, complexos que parecem durar horas, aí eu acordo e são 10h13min. -Exato. Então aqueles seis a doze minutos de atividade cerebral podem ser a sua vida inteira. Você é aquela velha, olhando para trás e vendo tudo (ALMEIDA, 2007: 47)

A relação entre espaço e tempo torna-se, portanto, processual, mutável e dinâmica. Em um mesmo tempo determinado, pode-se ocorrer vários fenômenos simultâneos, que o tornarão longo ou curto de acordo com a circunstância.

A montagem do filme como um todo também pode ser associada aos conceitos de tempo e espaço líquidos de Bauman. O enredo não se adequa a linha temporal típica, de início, meio e fim. Do contrário, se desenvolve em uma linha cíclica, sem relação entre os personagens, sem clímax, e sem um final marcado como final. O filme se conclui com 
uma cena semelhante às outras que aparecem ao longo da obra: o protagonista flutuando no ar sem rumo definido. Partindo do pressuposto de que tempo é aquilo que é necessário para ocorrer certo espaço, a necessidade de uma cronologia e uma linha temporal exata torna-se relativa.

Os espaços no filme também podem ser definidos pela dinâmica espacial líquida. A não relação direta entre as cenas e lugares, a inexistência de um lugar específico (um país, uma cidade, uma casa), a ausência do protagonista em todas as cenas, nos indica a possibilidade da ocorrência de vários diálogos e experiências de vida ocorrendo simultaneamente, como indica a variante espacial de Bauman com o advento das novas tecnologias e sistemas de informação.

\section{Indivíduo}

Feita a discussão sobre espaço e tempo, partimos para a discussão d conceito de indivíduo. Como já foi referenciado, o indivíduo na Modernidade Líquida é o centro responsabilidade e ação. Ele é livre para encontrar sua identidade e se autoconstruir; e possui dentro de si tudo que precisa para transgredir seus limites. No filme, assim como na obra de Bauman, vemos uma relação bastante complexa desse indivíduo com a liberdade que essa modernidade o proporcionou. Liberdade essa que não se sabe se é uma benção ou uma maldição (BAUMAN, 2001:26).

Na cena 6 do filme, o personagem que conversa com o protagonista aponta as diversas indagações a respeito da liberdade individual. A respeito do indivíduo existe a seguinte fala: 
"Quem você é" se baseia nas livres escolhas que faz ou pelas quais se responsabiliza. Só será responsável ou declarado culpado, ou respeitado pelas coisas que se faz pela própria escolha. A escolha retorna sem cessar e não temos solução (ALMEIDA, 2007: 47).

O indivíduo está livre para escolher, mas o personagem deixa claro que o ele não pode escolher se quer ser livre ou não. Pois a "escolha retorna sem cessar". Em seu capítulo sobre a emancipação, Bauman fala sobre como o processo de individualização - ou seja, quando as responsabilidades pelos atos e suas consequências são designadas somente ao indivíduo - é inevitável; de como é impossível fugir dele quando se vive na era moderna.

Mas a modernidade como um todo - sólida e líquida - carrega essa característica; o que vai diferir a fala do personagem, que o trará mais perto da modernidade líquida é o momento posterior no qual ele relaciona as ações humanas com as determinações físicas: “[...] você estende seu braço, parece uma ação livre sua, cada parte desse processo é governada por leis físicas, químicas ou elétricas, etc.”. Até aqui, percebemos que o personagem enxerga uma limitação para a liberdade humana; através da referência as determinações físicas. Se é Deus ou a física algo limita nossos atos, essa certeza, para o personagem caiu por terra a partir do momento em que se descobre a quântica. A física quântica introduz o caos à certeza científica. A Ciência, que havia substituído Deus, segundo o personagem, agora é tão incerta quanto ele.

Esse diálogo nos introduz um novo elemento, que é característica que nos difere da primeira modernidade: a incerteza (BAUMAN, 
2001:37). Se até mesmo a física, (teoricamente) a mais objetiva das ciências está trabalhando com leis probabilísticas e caóticas, os homens deixam de ser máquinas mecânicas e passam a viver num mundo em que o caos é cientificamente provado. O fim do diálogo demonstra a dificuldade do humano em aceitar que não existem regras préestabelecidas, não existe um telos e o futuro é inconstante: "eu prefiro ser uma engrenagem, em uma máquina determinista e física do que uma transgressão aleatória”.

A fluidez da Modernidade Líquida expressa a incerteza em quase todos os campos da vida. Como o fluído não prende o tempo, o ser humano não tem balizas fixas para se segurar. Essa constante incerteza está presente em todo filme. Visto que ele é repleto de "diálogos" (que muitas vezes são monólogos) que não dão respostas às questões levantadas. Essas conversas suscitam as incertezas e a angústia delas em quem assiste ao filme. Em uma das cenas, duas personagens conversam sobre a velhice, e a identidade individual:

[...] digamos uma foto de um bebê, você pega uma imagem bidimensional e diz 'sou eu'. Para ligar o bebê dessa imagem estranha a você no presente. 'Esta sou eu quando tinha um ano, depois tive cabelos compridos e depois nos mudamos para Riverdole e aqui estou'... então a história necessária é, na verdade, uma ficção para tornar você e o bebê idênticos, para criar sua identidade (ALMEIDA, 2007: 51) .

Aqui quem vê o filme se questiona sobre a própria vida e identidade, e podem percebê-las como construções; mas o mais interessante é o fala seguinte na qual as características mais "naturalizadas" do ser 
humano, como sua história de vida e a relação com seu corpo são questionadas: "O engraçado é que nossas células se regeneram totalmente a cada sete anos, já fomos várias pessoas diferentes, e no entanto, sempre permanecemos, sem em essência nós mesmos" (ALMEIDA, 2007: 51). Nesse diálogo, através de argumentos científicos, embasados em Benedict Anderson e estudos sobre biologia as personagens questionam a própria essência humana e biológica do eu. O que seria o “eu”? Já que nós mesmos construímos uma ficção para que tenhamos uma identidade e nem biologicamente somos a mesma pessoa?

Junto com a dúvida sobre o a própria essência do ser humano, um outro conceito que também está explícito no livro de Hall traz a discussão incertezas sobre a linguística. O livro de Hall, publicado em 1992, traz um breve panorama de como o indivíduo é modificado pelas mudanças da modernidade e resulta no sujeito pós-moderno; estas modificações ocorrem devido às "rupturas nos discursos do conhecimento moderno" (HALL, 2005: 34), as quais já foram elencadas.

Uma destas rupturas, a virada linguística, pode ser percebida de forma clara em um momento específico do filme. Em certa cena, o protagonista realiza um diálogo com outra personagem, onde ela demonstra algumas inquietações sobre a linguagem. Hall considera que um dos descentramentos do indivíduo está justamente ligado à linguística estrutural, em especial ao trabalho de Ferdinand de Saussure. Para este linguista, nós, enquanto falantes de uma determinada língua, não somos autores das afirmações e nem dos significados da nossa fala, já que a língua é um sistema social e não individual (HALL, 2005: 40). Desta 
forma, quando falamos não expressamos apenas nossos pensamentos interiores, mas também significados que já estão inseridos na língua, devido ao nosso sistema cultural. Outra conclusão de Hall se deve também ao filósofo da linguagem Jacques Derrida, seus estudos mostram que não é possível fixar o significado de uma palavra, pois "elas sempre carregam ecos de outros significados que elas colocam em movimento" (HALL, 2005: 41). Podemos observar como isso se mostra no filme observando o seguinte trecho de um diálogo:

- O que é frustração? Ou o que é "raiva" ou "amor"? Quando eu digo amor, o som sai da minha boca e atinge o ouvido de outra pessoa viaja através de um canal labiríntico em seu cérebro através das memórias de amor ou de falta de amor. $\mathrm{O}$ outro diz que compreende, mas como sei disso? As palavras são inertes. São apenas símbolos. Estão mortas, sabe? [...] E, ainda assim, quando nos comunicamos uns com os outros e sentimos ter feito uma ligação, e termos sido compreendidos, acho que temos uma sensação quase como uma comunhão espiritual (ALMEIDA, 2007: 45).

Neste diálogo percebemos a inquietação da personagem sobre o significado das palavras, quando elas representam o abstrato, o intangível, é perceptível que existe certo desconforto sobre o que determinado conceito realmente representa. Segundo a personagem, uma palavra pode significar coisas diferentes para pessoas diferentes, ou seja, nunca podemos ter certeza de que fomos realmente compreendidos. Isso se deve, segundo aponta Hall, pelo fato de que "nossas afirmações são baseadas em proposições e premissas das quais nós não temos consciência, mas que são, por assim dizer, conduzidas na corrente sanguínea de 
nossa língua” (HALL, 2005: 41). Cada palavra tem sua história, um "antes" e um "depois", por mais que se procure dar a ela uma identidade fechada e única, o significado dela está em constante perturbação e possui variadas conotações sob as quais não temos controle. Por fim, podemos concluir que a metáfora do líquido utilizada por Bauman também se aplica para a questão da linguagem, já que há uma dificuldade de mantê-la fixa devido à instabilidade de seus significados. E a conclusão de que não e possível, através da língua, nos comunicarmos de maneira completa, introduz mais uma dúvida no cotidiano fluido, será que estamos sendo compreendidos?

Essa incerteza a respeito do próprio indivíduo e sua comunicação está aliada, na Modernidade Líquida, ao fim da busca e da crença em uma sociedade perfeita. Bauman afirma que a sociedade atual barra o questionamento de sua ordem por conta de sua futilidade; desse modo, apesar de não abrir mão da crítica à sociedade, o indivíduo não consegue enxergar uma saída. Ele não vê mais, como acontecia na primeira modernidade, uma chance na ação coletiva. Essa ação coletiva é barrada porque os indivíduos não conseguem encontrar um "causa comum”, pois o discurso da "sociedade justa" foi trocado pelo discurso dos "direitos humanos"; o direito de cada um buscar um modo de felicidade (BAUMAN, 2001: 37).

Podemos perceber essa angústia do sujeito pós- moderno em diversas cenas do filme. O indivíduo não consegue sair da crítica. Ele não consegue enxergar além dele mesmo, assim, suas ações para tentar mudar a sociedade são isoladas e individuais. 
Na cena 5 podemos enxergar essas questões. O protagonista ouve um personagem falando sobre a alienação. Ele comenta como a mídia consegue manter as pessoas passivas, através do ato meramente simbólico das eleições. Sua crítica é abrangente, ele percebe que o problema não é individual. Antes de atear fogo em si mesmo essa personagem faz a seguinte fala: "É chegado o momento de eu projetar minhas inadequações e insatisfações nos esquemas sociopolíticos e científico, e deixar que a minha própria falta de voz seja ouvida" (ALMEIDA, 2007: 47). O protesto é individual. O personagem busca ser ouvido através de seu ato individual; e apesar dele perceber que a culpa do caos do sistema é coletiva, o seu modo de "atacar" a ordem é individual.

De outra maneira a cena 12 expõe o mesmo problema: o questionamento do sistema. Um grupo de pessoas caminham falando que a sociedade é uma fraude. Eles questionam o conforto, a felicidade, a sociedade do consumo, etc. Caminhando os personagens encontram um velho pendurado num poste e o diálogo é o seguinte:

- O que está fazendo?

- Não sei bem.

- Precisa de ajuda para descer, senhor?

- Não, acho que não.

- Velho burro. Não é pior que nós, ele é pura ação, sem teoria.

- Nós somos pura teoria sem ação (ALMEIDA, 2007:57).

Aqui o questionamento da ordem é barrado pela falta de ação. Os personagens reconhecem isso, que apesar de compreenderem a sociedade em que vivem e perceberem onde devem mudar eles não conseguem 
partir para ação. Bauman comenta, que se os tempos das revoluções passaram é porque não existem mais edifícios que alojam o poder, e mesmo se existirem, dificilmente os revolucionários conseguiriam transformá-lo em uma ferramenta revolucionária. Essa liberdade do indivíduo faz com que ele não consiga tornar coletiva as suas insatisfações individuais, não consiga achar o "edifício".

A discussão elaborada no decorrer do trabalho teve por objetivo questionar elementos da "modernidade líquida" de Bauman e o filme de Richard Linklater produzido em 2001, Waking Life. A esse respeito podemos concluir que o trabalho do diretor, ao buscar referências diretas de historiadores e sociólogos de seu tempo para elaborar o roteiro, aproximou-se muitas vezes da liquidez proposta por Zygmunt Bauman. Além disso, o contexto de produção da fonte analisada também condiz com a analise do autor, uma vez que os Estados Unidos são a marca referencial da globalização, da mistura de diferentes perspectivas de mundo, e está constantemente em exposição em noticiários e produções midiáticas que constroem a sociedade fluida ocidental, sob influencia de fatores internos e globais.

\section{Referências Bibliográficas}

ALMEIDA, Anne Caroline Santilli de. Análise acerca do filme de animação Waking Life. Monografia (graduação em Artes Plásticas) - Universidade do Estado de Santa Catarina, Centro de Artes, Florianópolis, 2007.

BAUMAN, Zygmunt. Modernidade líquida. Rio de Janeiro: Jorge Zahar, 2001. 
Cadernos de Clio, Curitiba, n. ${ }^{\circ}$ 5, 2014

BORGES, Eduardo Jose Santos. Cinema e História: O Encontro de Dois Mundos. Praxis (Salvador), v. 2, 2005.

FERRO, Marc. Cinema e História. São Paulo: Paz e Terra, 1992.

HALL, Stuart. A identidade cultural da pós-modernidade. $10^{\mathrm{a}}$ ed. Rio de Janeiro: DP\&A editora, 2005.

KORNIS, Mônica. História e Cinema: um debate metodológico. Revista Estudos Históricos, Brasil, 5, jul.1992.

MORETTIN, Eduardo V. O cinema como fonte histórica na obra de Marc Ferro. História. Questões e Debates, Curitiba, v. 20, n. 38, 2003. 